\title{
Tumor-specific expression detected with the use of an expression vector driven by human telomerase reverse transcriptase gene promoter
}

\author{
JIAJUN YIN, PANFENG FU, XIAOBO WANG, GANG JIN, and RUIJUAN XIU \\ DALIAN and BEIJING, CHINA
}

To construct the tumor-specific expression vector driven by human telomerase reserve transcriptase gene promoter, we amplified a fragment of the enhanced green fluorescent protein (EGFP) gene from the PEGFP-N1 plasmid and cloned it into the multiple cloning site of the pLNCX vector, then named the recombinant as pLNCX-EGFP. The fragment of human telomerase reverse transcriptase gene promoter (hTERT) was amplified from the human genome with the use of human telomerase reserve transcriptase gene-specific primers and cloned into the pLNCXEGFP vector, from which the cytomegalovirus promoter had previously been removed through the use of restriction enzymes, in sense orientation relative to the green fluorescent protein coding sequence. Then the expression vector pLNTEGFP- under the control of the human telomerase reserve transcriptase gene promoter, which contains green fluorescent protein reporter gene-was successfully constructed. To detect the transcriptional activity of the human telomerase reserve transcriptase gene promoter, we conducted transient transfection of this specific expression vector into human lung fibroblast (HLF) cell lines with high telomerase activity and normal human fetal lung fibroblast (WI38) cell lines without telomerase activity. The results of transient transfection showed that the pLNT-EGFP vector strongly expressed the green fluorescent protein reporter gene in telomerasepositive cells but not in telomerase-negative cells. (J Lab Clin Med 2004; 144:302-6)

\begin{abstract}
Abbreviations: $\mathrm{bp}=$ base pair; $\mathrm{cDNA}=$ complementary DNA; CMV = cytomegalovirus; EGFP = enhanced green fluorescent protein; ELISA = enzyme-linked immunosorbent assay; GFP = green fluorescent protein; HLF = human lung fibroblast; hTERT = human telomerase reverse transcriptase; $\mathrm{hTR}=$ RNA component of human telomerase; $\mathrm{kb}=$ kilobase; mRNA = messenger RNA; PCR = polymerase chain reaction; RT = reverse transcription; WI38 = normal human fetal lung fibroblast
\end{abstract}

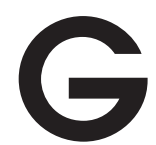
ene therapy is a promising approach to the treatment of malignant tumors, but problems are associated with its use. One of these problems is nonspecificity: The delivery system may nonspecifically infect adjacent cells, many of which are normal. This indiscriminate transfection can prevent the application of this technique in the treatment of

From the Department of General Surgery, Dalian Railway Hospital and Fourth Affiliated Hospital of Dalian Medical University Dalian, China; the Institute of Microcirculation Chinese Academy of Medical Sciences Peking Union Medical College, Beijing, China, the Department of Hematology, Second Affiliated Hospital of Dalian Medical University, Dalian, China; and the Institute of Mechanics Chinese Academy of Sciences, Beijing, China. malignant tumors. There are several approaches to overcoming this problem. One is to manipulate the surface proteins on the virus so that the virus can specifically infect certain types of cells. Another avenue is to use a tumor-specific promoter to regulate the

Submitted for publication January 25, 2004; revision submitted August 13, 2004; accepted for publication September 3, 2004.

Reprint requests: Xiu Ruijuan, MD, PhD, Institute of Microcirculation, Chinese Academy of Medical Sciences, Peking Union Medical College, Beijing 100005, China; e-mail: xiurj@yahoo.com.cn.

0022-2143/\$ - see front matter

(c) 2004 Elsevier Inc. All rights reserved.

doi:10.1016/j.lab.2004.09.010 
expression of the therapeutic gene delivered into tumor cells.

Telomerase is an RNA-dependent DNA polymerase that synthesizes telomeric DNA. Telomerase consists of several components, but the most important component responsible for the enzymatic activity of telomerase is hTERT, the catalytic subunit of telomerase, which is highly active in immortalized cells and in more than $85 \%$ of human cancers but quiescent in most normal somatic cells. ${ }^{1,2}$ Because hTERT expression is regulated at the transcriptional level, the hTERT promoter can be used to regulate the targeted expression of the therapeutic genes. We therefore constructed a retroviral vector driven by the hTERT promoter specifically to express a GFP reporter gene in cells with high telomerase activity and evaluated its activity in vitro.

\section{METHODS}

Cells. Human normal fibroblast HLF, WI38, and human breast-cancer MCF-7 cells were purchased from the Cell Bank of the Chinese Academy of Science (Shanghai, China). Cells were cultured in RPMI-1640 medium (Gibco-BRL, Grand Island, NY) supplemented with $10 \%$ heat-inactivated fetal calf serum (Gibco-BRL), $100 \mathrm{U} / \mathrm{mL}$ penicillin, and 100 $\mu \mathrm{g} / \mathrm{mL}$ streptomycin under an atmosphere of $95 \%$ air $5 \%$ $\mathrm{CO}_{2}$ at $37^{\circ} \mathrm{C}$. HLF and MCF-7 cells were positive for telomerase, whereas WI38 cells were negative.

Clone of the hTERT gene promoter. The $1.1-\mathrm{kb}$ fragment of hTERT gene promoter was amplified from the human genome of circulating blood cells with the use of hTERTspecific primers (5'-AAAGGATCCGTCTGGATTCCTGGGAAGTC-3' as forward and 5'-AAAAAGCTTGACGCAGCGCTGCCTGAAAC-3 \pm as reverse) in accordance with the method set forth by Wick, Zubov, and Hagen, ${ }^{3}$ then analyzed on an ABI Prism 377 automated DNA sequencer (Applied Biosystems, Foster City, Calif).

Construction of the expression vector driven by the hTERT promoter. We amplified the 720-bp fragment of EGFP gene from the pEGFP-N1 plasmid using EGFP-specific primers (5'-CAAAGCTTATGGTGAGCAAGGGCGAGGA-3' as forward and 5'-CAATCGATTTACTTGTACAGCTCGTCCA-3' as reverse). This 720-bp fragment and retroviral vector $\mathrm{pLNCX}$ were digested with the use of Hind III and Cla I. After they were recovered and purified, the EGFP fragment and vector were ligated. The reaction mixture was transducted into Escherichia coli JM109, and the resistance colonies were screened with the use of ampicillin, after which the plasmids were extracted and sequenced. The CMV promoter region was removed from the plasmid proved by means of sequencing with Hind III and $B a m H$ I, and the vector fragment was recovered. The hTERT promoter fragment was digested with the use of Hind III and BamH I, after which the $1.1-\mathrm{kb}$ promoter cDNA and vector fragment were ligated. The reaction mixture was transducted into $E$ coli JM109, and the resistance colonies were screened by ampicillin. Next, plasmids were extracted and sequenced. The design of the specific vector is shown in Fig 1.

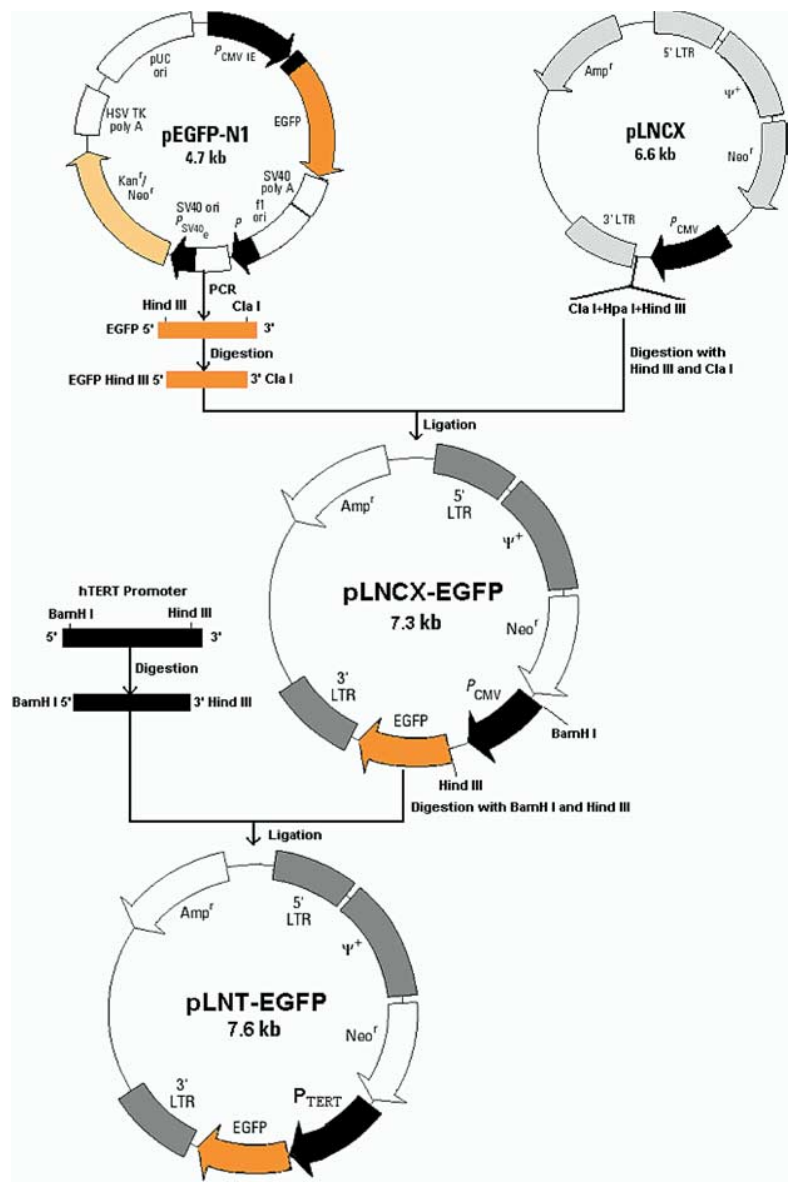

Fig 1. The design of tumor-specific expression vector driven by human telomerase reverse transcriptase gene promoter. An EGFP gene fragment was amplified from the pEGFP-N1 plasmid and ligated with retroviral vector pLNCX after both were digested with Hind III and Cla I. The CMV promoter region was replaced with an hTERT promoter fragment digested with Hind III and BamH I.

Analysis of telomerase activity in cells. We assessed telomerase activity using a Telomerase PCR ELISA kit (Roche, Mannheim, Germany) in accordance with the manufacturer's instructions. We harvested $2 \times 10^{5}$ cells and counted them with the use of trypan-blue staining. The extraction of telomerase and the telomerase repeat amplication protocol (TRAP) reaction were performed in accordance with the kit's protocols. Conditions for the TRAP reaction are as follows: After 30 minutes' incubation at $25^{\circ} \mathrm{C}$ for TRAP extension and 5 minutes at $94^{\circ} \mathrm{C}$ for telomerase inactivation, the reaction mixture is subjected to PCR amplification in a thermal cycler for 30 cycles, including denaturation at $94^{\circ} \mathrm{C}$ for 30 seconds, annealing at $50^{\circ} \mathrm{C}$ for 30 seconds, polymerization at $72^{\circ} \mathrm{C}$ for 90 seconds, and extension at $72^{\circ} \mathrm{C}$ for 10 minutes. After TRAP, we performed hybridization and ELISA in each sample in accordance with the manufacturer's protocol. Using a microtiter-plate reader, we measured the absorbance of the samples at $450 \mathrm{~nm}$ (reference wavelength $690 \mathrm{~nm}$ ). The 
extract of human telomerase-positive embryonic kidney cell line 293 was used as a positive control, and heat treatment of the cell extract for 10 minutes at $65^{\circ} \mathrm{C}$ before the TRAP reaction was used to inactivate telomerase protein to produce negative controls.

Transient-transfection assay. To determine whether GFP expression driven by the hTERT promoter is limited to telomerase-positive cells, we performed transient-transfection assays with the use of LipofectAMINE-mediated gene transfer (Invitrogen, Carlsbad, Calif) as described previously. ${ }^{4}$ On the day before transfection, cells were seeded at a density of $2 \times 10^{5} / \mathrm{mL}$ in 6 -well plates. Targeted expression vectors under the control of the hTERT promoter were transfected into the cells. Twenty-four hours after transfection, the medium was changed and the cells were incubated for an additional 48 hours. Cells were visualized with the use of an inverted fluorescence microscope to detect GFP expression 48 and 72 hours after transfection. We harvested cells to detect the expression of GFP mRNA 72 hours after transfection.

RT-PCR analysis. We used $1 \mu \mathrm{g}$ of RNA for first-strand cDNA synthesis with the TaKaRa RNA PCR Kit version 2.1 (TaKaRa BIOTECH, Japan). Next we amplified the cDNAs with the use of PCR involving Taq polymerase(TaKaRa BIOTECH, Japan) and a GFP-specific primer set (5'CAAAGCTTATGGTGAGCAAGGGCGAGGA- $3^{\prime}$ as forward primer and 5'-CAATCGATTTACTTGTACAGCTCGTCCA-3' as reverse primer). PCR was carried out for 30 cycles, each consisting of 2 minutes at $94^{\circ} \mathrm{C}$ for predenaturation, 30 seconds at $94^{\circ} \mathrm{C}$ for denaturation, 30 seconds at $58^{\circ} \mathrm{C}$ for annealing, and 1 minute at $72^{\circ} \mathrm{C}$ for extension. Each PCR product was electrophoretically separated in $1.5 \%$ agarose gel. The human Glyseraldehyde-3-phosphate dehydrogenase (hGAPDH) PCR products from the same RNA samples were amplified as internal controls.

Statistical analysis. Data are expressed as means \pm SD. Statistical analyses were conducted with the use of Student's $t$ test. We considered $P$ values of less than .05 statistically significant.

\section{RESULTS}

Cloning of the hTERT gene promoter. Approximately $1.1 \mathrm{~kb}$ of the hTERT promoter sequence was cloned, then analyzed on an ABI Prism 377 automated DNA sequencer. The nucleotide-sequence data reported here match the GeneBank nucleotide sequences with the accession number AF097365 (Fig 2).

Telomerase activity in cells. To detect the transcriptional activity of the hTERT promoter, we selected HLF, MCF-7, and WI38 cells; HLF and MCF-7 cells express telomerase, but WI38 cells do not. Next we performed TRAP PCR ELISA assays. As shown in Fig 3, telomerase activity was demonstrated in HLF and MCF-7 cell lines, but WI38 cell lines did not express detectable activity. This finding corresponded with the results of earlier studies. ${ }^{5-7}$
1 gggagaccca gaagtttctc geccettaga tccaaacttg agcaaccegg agtctggatt 61 cetgggaagt cctcagctgt cetgeggttg tgceggggec ccaggtctgg aggggaccag 121 tggcegtgtg gettctactg ctgggetgga agtcgggect cctagctctg cagtccgagg 181 cttggagcca ggtgectgga cccegagget gectccacc ctgtgeggge gggatgtgac 241 cagatgttgg cetcatctgc cagacagagt gecggggecc agggtcaagg ccgttgtggc 301 tggtgtgagg cgeceggtge geggecagca ggagcgectg getccatttc ccaccetttc 361 tcgacgggac cgccccggtg ggtgattaac agatttgggg tggtttgctc atggtgggga 421 cccetcgecg cetgagaacc tgcaaagaga aatgacggge ctgtgtcaag gagcccaagt 481 cgcggggaag tgttgcaggg aggcactccg ggaggtcceg cgtgccegtc cagggagcaa 541 tgcgtcctcg ggttcgtccc cagccgcgtc tacgegcetc cgtcctccce ttcacgtccg 601 gcattcgtgg tgeceggagc ccgacgecce gegtccggac ctggaggcag ccctgggtct 661 ccggatcagg ccagcggeca aagggtcgec gcacgcacct gttcccaggg cctccacatc 721 atggeccetc cetcgggtta ccccacagcc taggecgatt cgacetctct ccgetggggc 781 cctcgctgge gtccetgcac cctgggagcg cgagcggege gegggegggg aagcgeggec 841 cagacccceg ggtccgeccg gagcagctge getgtcgggg ccaggecggg ctccagtgg 901 attcgegggc acagacgecc aggaccgegc ttcccacgtg geggagggac tggggacceg 961 ggcaccegtc ctgcecttc accttccagc tcegectcct cegcgeggac ccegeccegt 1021 cccgaccect cecgggtcce cggeccagcc cectceggge cetccagec cetccettc 1081 ctttccgegg ceccgecetc tcctcgegge gegagtttca ggcagegetg cgtcetgetg 1141 cgcacgtggg aagccetgge cceggecacc cecgegatg

Fig. 2. The sequence of the hTERT promoter. Boldface letters represent the sequence used in this experiment.

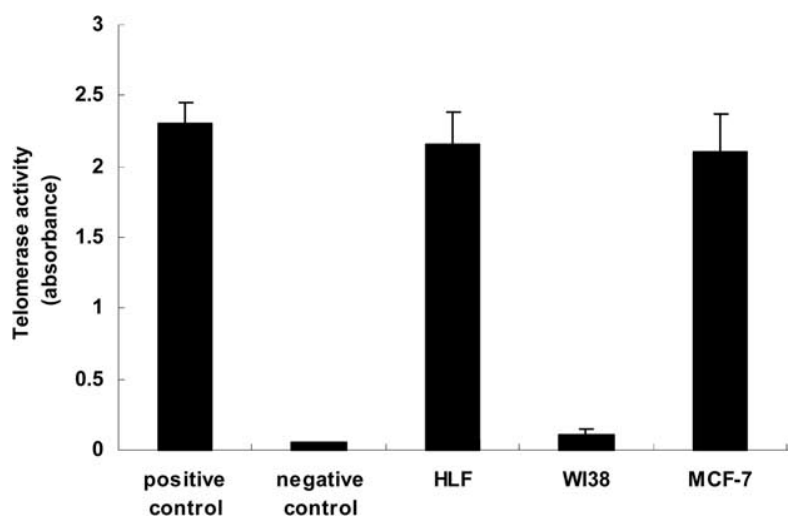

Fig 3. Telomerase-activity analysis of 3 cell lines with the use of TRAP PCR ELISA. HLF and MCF-7 cells (which express telomerase activity) and WI38 cells (which do not) were selected for the assay of telomerase activity. Telomerase activity was demonstrated in the HLF and MCF-7 cell lines, but WI38 cells lines did not demonstrate detectable telomerase activity.

Transcriptional activity of hTERT promoter in cells. To confirm that the transcriptional activity of hTERT promoter is only observed in cells with telomerase activity, we conducted transient transfection of GFP reporter plasmids driven by hTERT promoter. As shown in Fig 4, the expression of GFP was observed in HLF and MCF-7 cells with telomerase activity 48 and 72 hours after transfection. In contrast, the expression of GFP was not observed in WI38 cells, which were without telomerase activity. To detect the transcriptional level of GFP mRNA, we collected cells 72 hours after transfection and analyzed them with the use of RT-PCR. The results showed transcription of GFP mRNA in HLF and MCF-7 cells but not in WI38 cells (Fig 5). 
Fig 4. Transient-transfection analysis of hTERT-promoter transcriptional activities. A, Inverted fluorescence microscopy of GFP expression of HLF cells 48 hours after transfection (original magnification $200 \times$ ). B, Light microscopy of HLF cells 48 hours after transfection (original magnification $200 \times$ ). C, Inverted fluorescence microscopy of GFP expression of HLF cells 72 hours after transfection (original magnification $200 \times$ ). D, Light microscopy of HLF cells 72 hours after transfection (original magnification $200 \times$ ). E, Inverted fluorescence microscopy of WI38 cells 48 hours after transfection (original magnification $200 \times$ ). F, Light microscopy of WI38 cells 48 hours after transfection (original magnification $200 \times$ ). G, Inverted fluorescence microscopy of WI38 cells 72 hours after transfection (original magnification $200 \times$ ). H, Light microscopy of WI38 cells 72 hours after transfection (original magnification $200 \times$ ). I, Inverted fluorescence microscopy of GFP expression in MCF- 7 cells 48 hours after transfection (original magnification $100 \times$ ). J, Light microscopy of MCF-7 cells 48 hours after transfection (original magnification $100 \times$ ). K, Inverted fluorescence microscopy of GFP expression by MCF-7 cells 72 hours after transfection (original magnification $100 \times)$. L, Light microscopy of MCF-7 cells 72 hours after transfection (original magnification $100 \times$ ).

\section{DISCUSSION}

Telomerase is a ribonucleoprotein enzyme that adds telomeric repeats to the end of chromosomes. ${ }^{8}$ The vast majority of malignant tumors express telomerase whereas most normal cells do not. ${ }^{9} 10$ Therefore, telomerase may be a good candidate for targeted therapy. Three components of the human telomerase have been identified: hTR, the telomerase-associated protein TEP1, and hTERT. Although both hTR and hTERT are necessary for telomerase activity, their expression patterns are different. The expression of hTERT is associated with telomerase activity, whereas the expression of hTR is also detected in telomerase-negative cells. ${ }^{11}$ In other words, hTERT is the major determinant of telomerase activity. The hTERT gene is highly active in tumor cells but repressed in most normal cells, and its expression is regulated at the transcription level. More recently, several groups have cloned and characterized the promoter region of the hTERT gene. ${ }^{12,13}$ The transcriptional activity of the hTERT gene promoter was observed exclusively in telomerase-positive cells. ${ }^{14} \mathrm{We}$ therefore hypothesized that the hTERT promoter could be used for the expression of the tumor-specific transgene.

In the treatment of tumors through the transfer of apoptosis-inducible genes, it is essential to restrict the expression of the gene in question to tumor cells. If the apoptosis-inducible gene transduces all cells with which it comes into contact, normal cells will also be subject to apoptosis. We can solve this problem by using targeted expression vector. On the basis of the finding that the hTERT promoter is active only in telomerase-positive cells such as tumor cells, we con-
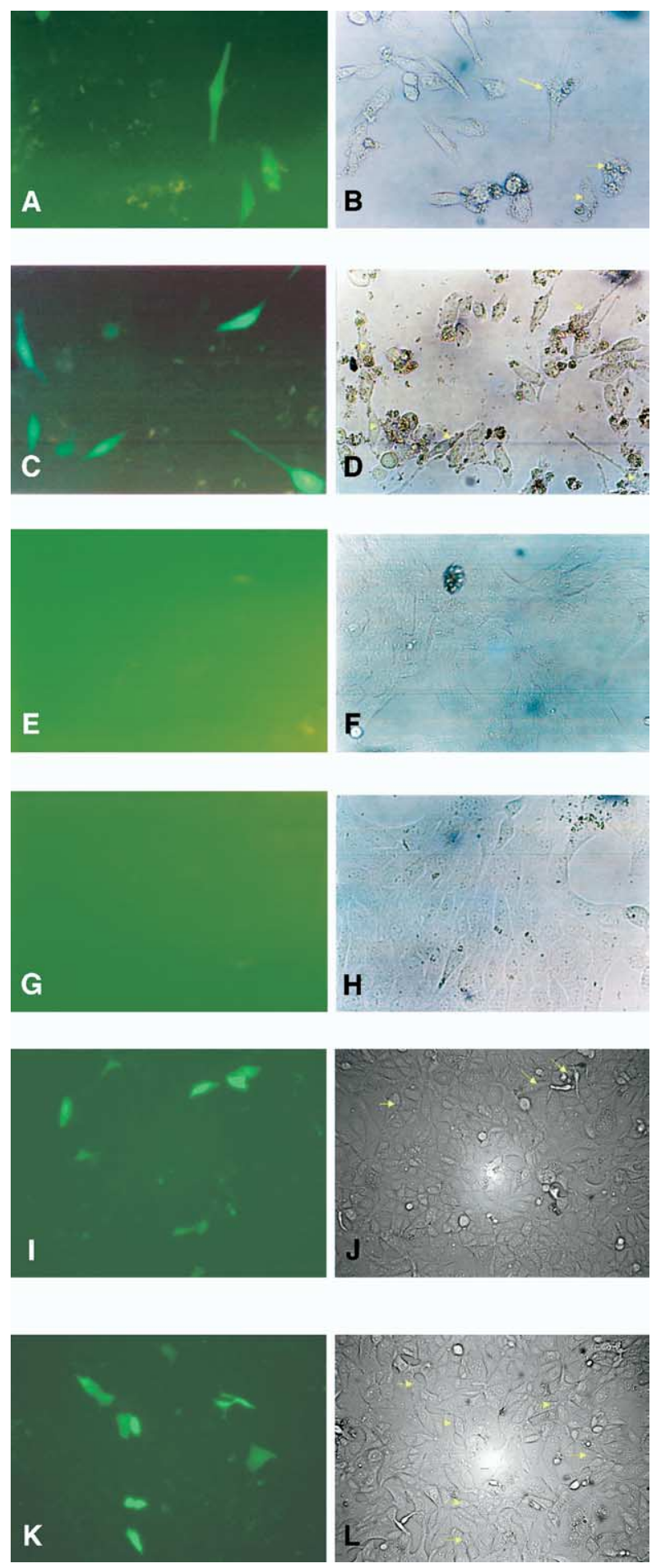

structed a tumor-specific expression vector driven by human telomerase reserve transcription gene promotor.

We observed the transcriptional activity of the hTERT promoter in 3 cell lines. The hTERT promoter construct showed significant transcriptional activity in 


\section{HLF MCF-7 WI38}

\section{GFP}

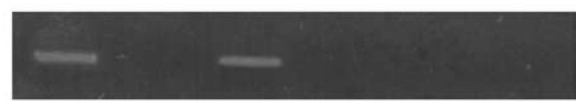

GAPDH

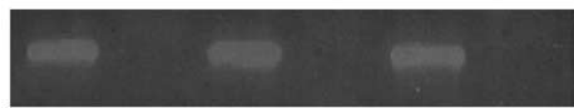

Fig 5. RT-PCR analysis of cells transfected by GFP reporter plasmids driven by hTERT promoter.

HLF and MCF-7 cells, which express telomerase activity, and the GFP gene could be transcribed and expressed, whereas transcriptional activity of the hTERT promoter was not observed in telomerase-negative WI38 cells. The telomerase-specific expression vector driven by the hTERT promoter may therefore be a novel and promising targeting approach for the treatment of tumors with telomerase activity. We can clone an apoptosis-inducible gene into this vector, and the apoptosis-inducible gene is under the control of the hTERT promoter. The specificity of apoptosis-inducible gene expression by the hTERT promoter could thus restrict the therapeutic effect to telomerase-positive tumor cells and alleviate the detrimental effect on normal cells without telomerase.

One of the major concerns with regard to the use of apoptosis-inducible gene driven by the hTERT promoter is its potential toxicity to stem cells. However, evidence suggests that hTERT is not active in the $\mathrm{G}_{0}$ stage, and stem cells are generally quiescent. ${ }^{9,15}$ Of course, more experiments should be conducted to investigate the therapeutic effect of the specific expression vector on tumors and the potential negative effect on normal cells. In summary, we demonstrate here that expression of the tumor-specific expression vector driven by hTERT gene promoter is restricted to telomerase-positive cells and is not seen in normal cells without telomerase activity. We expect that this approach will increase the safety and effectiveness of gene therapy.

\section{REFERENCES}

1. Kim NW, Piatyszek MA, Prowse KR, Harley CB, West MD, Ho PL, et al. Specific association of human telomerase activity with immortal cells and cancer. Science 1994;266:2011-5.

2. Shay JW, Bacchetti S. A survey of telomerase activity in human cancer. Eur J Cancer 1997;33:787-91.

3. Wick M, Zubov D, Hagen G. Genomic organization and promoter characterization of the gene encoding the human telomerase reverse transcriptase (hTERT). Gene 1999;232:97-106.

4. Kondo S, Tanaka Y, Kondo Y, Ishizaka Y, Hitomi M, Haqqi T, et al. Retroviral transfer of CPP32beta gene into malignant gliomas in vitro and in vivo. Cancer Res 1998;58:962-7.

5. Meyerson M, Counter CM, Eaton EN, Ellisen LW, Steiner P, Caddle SD, et al. hEST2, the putative human telomerase catalytic subunit gene, is up-regulated in tumor cells and during immortalization. Cell 1997;90:785-95.

6. Nakamura TM, Morin GB, Chapman KB, Weinrich SL, Andrews WH, Lingner J, et al. Telomerase catalytic subunit homologs from fission yeast and human. Science 1997;277: 955-9.

7. Ramachandran C, Fonseca HB, Jhabvala P, Escalon EA, Melnick SJ. Curcumin inhibits telomerase activity through human telomerase reverse transcritpase in MCF-7 breast cancer cell line. Cancer Lett 2002;184:1-6.

8. Blackburn EH. Structure and function of telomeres. Nature 1991; 350:569-73.

9. Kim NW. Clinical implications of telomerase in cancer. Eur J Cancer 1997;33:781-6.

10. Kyo S, Inoue M. Complex regulatory mechanisms of telomerase activity in normal and cancer cells: how can we apply them for cancer therapy? Oncogene 2002;21:688-97.

11. Bodnar AG, Ouellette M, Frolkis M, Holt SE, Chiu CP, Morin $\mathrm{GB}$, et al. Extension of life-span by introduction of telomerase into normal human cells. Science 1998;279:349-52.

12. Horikawa I, Cable PL, Afshari C, Barrett JC. Cloning and characterization of the promoter region of human telomerase reverse transcriptase gene. Cancer Res 1999;59:826-30.

13. Takakura M, Kyo S, Kanaya T, Hirano H, Takeda J, Yutsudo M, et al. Cloning of human telomerase catalytic subunit (hTERT) gene promoter and identification of proximal core promoter sequences essential for transcriptional activation in immortalized and cancer cells. Cancer Res 1999;59:551-7.

14. Kim E, Kim JH, Shin HY, Lee H, Yang JM, Kim J, et al. Ad-mTERT-delta19, a conditional replication-competent adenovirus driven by the human telomerase promoter, selectively replicates in and elicits cytopathic effect in a cancer cell-specific manner. Hum Gene Ther 2003;14:1415-28.

15. Holt SE, Aisner DL, Shay JW, Wright WE. Lack of cell cycle regulation of telomerase activity in human cells. Proc Natl Acad Sci U S A 1997;94:10687-92. 